\title{
Customer loyalty analysis of a commercial bank based on a structural equation model
}

\author{
H. Chi ${ }^{1}$, Y. Zhang ${ }^{1,2}$ \& J.-J. Wang ${ }^{1,2}$ \\ ${ }^{1}$ Institute of Policy and Management, \\ Chinese Academy of Sciences, People's Republic of China \\ ${ }^{2}$ Business School, University of Science and Technology of China, \\ People's Republic of China
}

\begin{abstract}
Customer Relationship Management (CRM) enjoys increasing attention since customers are known to be of pivotal importance to the long-term profitability and development of enterprises as well as commercial banks. With the competition among banks being more and more severe, customers' loyalty has become the decisive factor of a bank's profitability, as an increase in customer retention rate can be very profitable. In this paper, a structural equation model (SEM) is used to research into the measurement of customer loyalty and the factors that influence it. Based on an American Customer Satisfaction Index (ACSI) model, this model takes into consideration Chinese commercial banks' specific situations and improves the latent variables, manifest variables and the structure of the ACSI model. Then a partial least squares (PLS) approach is adopted to estimate the parameters in SEM. By using this model, further analysis can be conducted. A numerical example has been offered with the data deriving from a practical survey of a Chinese commercial bank. The results of the example have been analyzed and corresponding measures can be taken to improve services, thus increasing customer loyalty.

Keywords: customer loyalty, structural equation model (SEM), partial least squares (PLS) estimation procedure.
\end{abstract}

\section{Introduction}

Since China entered the World Trade Organization (WTO) in the year 2001, the opening pace of the Chinese financial industry has been much quicker. As a part 
of the WTO commitments, China will completely open her bank sector to foreign banks from 2007. Consequently, Chinese commercial banks will face more and more severe competition in the very near future.

The customer is the source of bank profit. Studies indicate that $20 \%$ customers of retail bank yield more than $100 \%$ profit $[1,2]$, therefore international banking industry pays much attention to CRM. Now CRM enjoys increasing attention since customers are known to be of pivotal importance to the long-term profitability and development of commercial banks, and the customercentric management idea has prevailed upon Chinese commercial banks. On the one hand, commercial banks must make great efforts to acquire new customers; on the other hand, they have to improve their service quality continuously in order to retain existing customers. M.T. Maloney and R.E. McCormick's study on customer value indicates that the cost of acquiring a new customer is $4 \sim 5$ times that of retaining an existing customer [3]. Therefore, commercial banks may increase their profit by improving the customer retention rate and customer loyalty. Thus it can be seen that customer loyalty of commercial banks has become a decisive factor of their profitability as well as an important part of their core competence.

There are many factors that influence customer loyalty. How to find out the most important ones from all of the factors and take corresponding measures to improve banks' service quality and customer loyalty is a crucial issue for Chinese commercial banks.

Most researchers consider that customer loyalty is the measurement of customer behaviours [4-10]. Some researchers think that customer loyalty is the probability of customers' purchasing the products and services of an enterprise or the probability of repeated purchase behaviour [4-6], others think that customer loyalty is the measurement of customers' purchase frequency and purchase quantity [7-10]. Gerpott et al. [11] analyzed the relations among customer satisfaction, customer loyalty and customer retention in the German mobile communications market by using the LISREL method. David W. Wallace et al. [12] studied customer loyalty in the context of multiple channel retail strategies. Using a binomial logit model, Kim and Yoon [13] researched into the determinants of subscriber churn and customer loyalty in the Korean mobile telephony market, etc.

These studies analyzed the strategies to improve customer loyalty and the factors that influence customer loyalty. But how to measure customer loyalty still needs further research, and quantitative studies on how customer loyalty is influenced are even scarcer.

In this paper, an SEM, a multiple equation causality model, is established to study customer loyalty of a Chinese commercial bank. Using SEM, the relations among variables could be analyzed, and customer loyalty could be measured. We can also find out which variables influence customer loyalty most, and the degree of such influence could be quantified. Therefore, we are able to know in which aspects a commercial bank should make improvements to enhance customer loyalty. 
The structure of this paper is as follows. In Section 2, a structural equation model is used to study how customer loyalty is influenced by other factors. A customer loyalty index (CLI) is put forward to measure customer loyalty. Section 3 explains why PLS is chosen to estimate the parameters. In Section 4, a numerical example has been offered. A questionnaire is designed for commercial banks' customers. Using this questionnaire, an investigation into a commercial bank's customers is conducted to collect the needed data. After testing the collected data, the PLS method is used to estimate the parameters of SEM. Furthermore, the factors that influence customer loyalty of the commercial bank are analyzed and the CLI is computed. Section 5 is our conclusions.

\section{Structural equation model of customer loyalty}

In some sense, customer loyalty is a kind of description of customers' psychological behaviour. Before choosing a corporation's products and services, customers always have certain anticipation, which affects their perception into the quality of products and services. Corporation's image and customer's perception into the quality of products and services jointly decide customers' satisfaction to this corporation. Ulteriorly, customer satisfaction will have some effects on customer loyalty. There are complicated causality among customer loyalty, perceived quality, perceived value and other variables. These variables are customers' psychological perception which could not be measured directly and accurately. Since SEM can be used to analyze the complicated relationship which involves latent variables, a structural equation model is constructed to study the measurement of commercial banks' customer loyalty and the factors that affect it.

SEM consists of two parts, the Measurement Model describing the relations between Latent Variables and their own measures, which are called Manifest Variables, and the Structure Equation Model describing the causal relations between Latent Variables. Variables like customer loyalty, perceived value and perceived quality describe customers' psychological perception. These variables can not be measured directly, so they are called Latent Variables. Every Latent Variable can be depicted by several variables which can be directly measured, and these variables are called Manifest Variables.

Many popular traditional methods (such as regression) allow dependent variables to have measurement errors, but they assume independent variables didn't have any errors. When neither dependent variables nor independent variables could be measured accurately, the traditional methods can not be applied to estimate the relationship among variables. In this circumstance, SEM can offer a better solution [14].

According to the customers' characteristics in China, the corresponding latent variables and manifest variables, the causal relations among them are designed by taking a new latent variable, corporation's image into consideration, as shown in Figure 1. 


\subsection{Structure equation model}

$$
\eta=B \eta+\Gamma \xi+\zeta
$$

where $\quad \eta^{\prime}=\left(\eta_{1}, \eta_{2}, \ldots, \eta_{m}\right)$ and $\xi^{\prime}=\left(\xi_{1}, \xi_{2}, \ldots, \xi_{n}\right)$ are vectors of latent endogenous and exogenous variables, respectively. $B(m \times n)$ is a matrix of coefficient parameters for $\eta$, and $\Gamma(m \times n)$ is a matrix of coefficient parameters for $\xi$.This implies that $E\left[\eta \zeta^{\prime}\right]=E\left[\xi \zeta^{\prime}\right]=E[\zeta]=0$.

\subsection{Measurement model}

$$
\begin{aligned}
& x=\Lambda_{x} \xi+\delta \\
& y=\Lambda_{y} \eta+\varepsilon
\end{aligned}
$$

where $x^{\prime}=\left(x_{1}, x_{2}, \ldots ., x_{q}\right)$ and $y^{\prime}=\left(y_{1}, y_{2}, \ldots ., y_{q}\right)$ are the manifest exogenous and endogenous variables, respectively. $\Lambda_{x}(q \times n)$ and $\Lambda_{y}(p \times m)$ are the corresponding factor loading matrices. Here we have

$$
E[\varepsilon]=E[\delta]=E\left[\eta \varepsilon^{\prime}\right]=E\left[\xi \delta^{\prime}\right]=0 .
$$

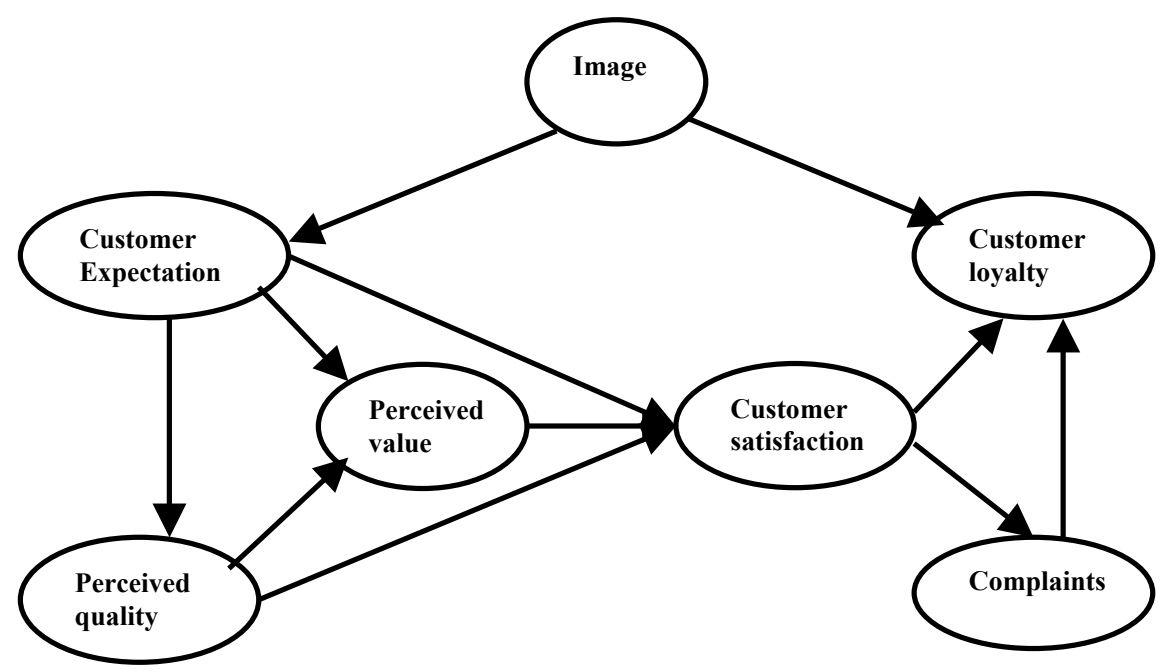

Figure 1: Customer loyalty structural equation model.

\subsection{Customer Loyalty Index (CLI)}

In order to measure Customer Loyalty, Customer Loyalty Index is presented as follows:

$$
C L I=\frac{10}{n}\left[\sum_{i=1}^{n} \pi_{i}\left(\frac{1}{m} \sum_{j=1}^{m} y_{i j}\right)\right]
$$


where $y_{i j}$ is the $j$ th customer's opinion on the $i$ th manifest variable of latent variable, Customer Loyalty. Suppose there are $m$ customers whose questionnaires are valid, and there are $n$ manifest variables. $\pi_{i}$ denotes the weight of the $i$ th manifest variable. In our questionnaire survey, all the manifest variables are scaled from 1 to 10 . Scale 1 expresses a very negative point of view on the product and service, while scale 10 a very positive opinion. We use $10 / n$ to normalize the index to ensure that the minimum possible value of CLI is 0 and its maximum possible value is equal to 100 . Therefore, high CLI indicates a high level of customer loyalty.

\section{Partial Least Squares (PLS) estimation procedure}

There are two well-known estimation methods of SEM with Latent Variables: LISREL and PLS [15]. LISREL is a maximum likelihood method, while PLS is a least squares method. LISREL assumes a multivariate normal distribution of observed variables, and tries to fit the observed covariance matrix with the model covariance matrix estimated by model parameters. Its goal is, in a sense, to predict (which is another expression for "fit") a covariance matrix, rather than predict dependent variables such as customer's behaviour. Furthermore, LISREL requires large sample sizes.

On the other hand, the PLS algorithm does not assume any distribution of the variables, and it specifies both the measurement and structural model as predictive relations. Once these predictive relations are specified, the estimation is a matter of minimizing the residual variances in the measurement models (measurement error variances) and structural equation models (prediction error variances). PLS weights are determined so that the least squares estimation of the model with given Latent Variables scores minimizes a combination of residual variances in the model. In addition, PLS only needs relatively small sample sizes.

The basic PLS algorithm for SEM with Latent Variables is as follows [16]:

We take Figure2 as an example to illustrate how PLS algorithm works.

Stage 1: Giving arbitrary starting values to the weights $\pi_{\eta 1}$ and $\pi_{\eta 2}$

Stage 2: Normalizing $\eta$ to unit variance and regressing it on $\mathrm{x} 1$ and $\mathrm{x} 2$.

Stage 3: Computing the predicted value of $\eta$ in this regression.

Stage 4: Normalizing $\eta$ to unit variance and regressing it on y1 and y2. So we can get new weights $\pi_{\eta_{1}}$ and $\pi_{\eta^{2}}$. An iteration is completed. Repeating stages 1 to 4 until convergence is obtained, and the procedure is repeated $\mathrm{k}$ times.

Stage 5: $\xi$ is estimated by a similar procedure.

Stage 6: At this point, the estimated $\hat{\eta}_{k}$ is regressed on the estimated $\hat{\xi}_{k}$ to obtain the structural relationship between the two. The regression of $\hat{\eta}_{k}$ on y1 and y2 gives the estimated criterion weights $\left(\pi_{\eta 1}, \pi_{\eta^{2}}\right)$ and the regression of $\hat{\xi}_{k}$ on x1 and $\mathrm{x} 2$ gives the estimated predictor weights $\left(\pi_{\xi 1}, \pi_{\xi_{2}}\right)$. 


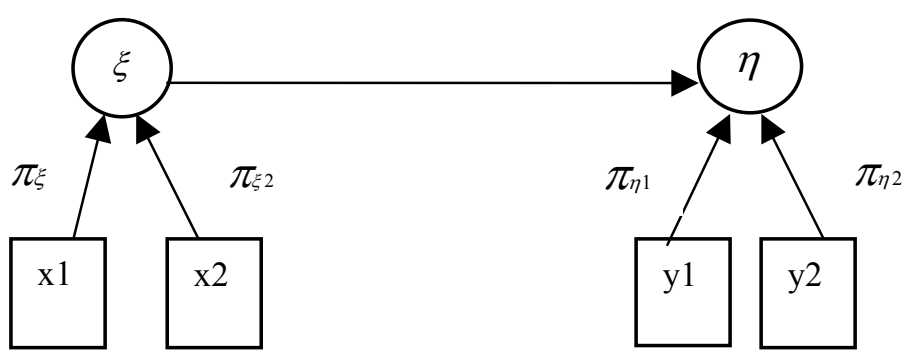

Figure 2: $\quad$ A simple example of SEM.

Table 1: $\quad$ The variables definition of customer loyalty SEM.

\begin{tabular}{|c|c|}
\hline Latent Variables & Manifest Variables \\
\hline \multirow{3}{*}{ Image $(\xi 1)$} & a) It is a leader in banking industry $(x 1)$ \\
\hline & b) Its services are customer-centric (x2) \\
\hline & c) What do you think of the whole image of this bank ( $\times 3)$ \\
\hline \multirow{3}{*}{$\begin{array}{l}\text { Customer Expectations } \\
\text { of the overall } \\
\text { quality }(\xi 2)\end{array}$} & $\begin{array}{l}\text { a) Expectations for the overall quality of this bank at the moment you } \\
\text { became customer of this bank (x4) }\end{array}$ \\
\hline & $\begin{array}{l}\text { b) Expectations for this bank to provide financial products and service } \\
\text { to meet your personal need }(\mathrm{x} 5)\end{array}$ \\
\hline & $\begin{array}{l}\text { c) How often did you expect that things could go wrong at this bank } \\
\text { (x6) }\end{array}$ \\
\hline \multirow{8}{*}{$\begin{array}{l}\text { Perceived Quality } \\
(\xi 3)\end{array}$} & a) Overall perceived quality (x7) \\
\hline & b) Service attitude of this bank's clerks (x8) \\
\hline & c) Professional efficiency of this bank's clerks (x9) \\
\hline & d) Is the business hours convenient for you (x10) \\
\hline & e) Accessibility of the bank's branches (x11) \\
\hline & f) The bank's capacity to meet customers' individual demand (x12) \\
\hline & g) Is the business procedure complicated (x13) \\
\hline & h) Customers' waiting time before being served (x14) \\
\hline \multirow[t]{2}{*}{ Perceived Value $(\xi 4)$} & $\begin{array}{l}\text { a) Given the fees and prices that you pay for this bank how would you } \\
\text { rate the quality of the products and services offered by the bank? (x15) }\end{array}$ \\
\hline & $\begin{array}{l}\text { b) Given the quality of the products and services offered by this bank } \\
\text { how do you think the fees and prices that you pay for them? (x16) }\end{array}$ \\
\hline \multirow{3}{*}{$\begin{array}{l}\text { Customer } \\
\text { Satisfaction }(\xi 5)\end{array}$} & a) Overall satisfaction (x17) \\
\hline & $\begin{array}{l}\text { b) The gap between your practical perception and your expectation } \\
\text { (x18) }\end{array}$ \\
\hline & $\begin{array}{l}\text { c) What do you think of this bank compared with your ideal bank? } \\
\text { (x19) }\end{array}$ \\
\hline \multirow[t]{2}{*}{$\begin{array}{l}\text { Customer } \\
\text { Complaints }(\xi 6)\end{array}$} & $\begin{array}{l}\text { a) How many times have you complained about this bank last year? } \\
\text { (x20) }\end{array}$ \\
\hline & b) How well, or poorly, was your complaints handled? (x21) \\
\hline \multirow[t]{3}{*}{$\begin{array}{l}\text { Customer Loyalty } \\
(\xi 7)\end{array}$} & $\begin{array}{l}\text { a) If you would need to choose a new bank how likely is it that you } \\
\text { would choose this bank again? (x22) }\end{array}$ \\
\hline & $\begin{array}{l}\text { b) If other banks decide to lower their fees and prices, but this bank } \\
\text { stays at the same level as today. At which level of difference would } \\
\text { you choose another bank? (x23) }\end{array}$ \\
\hline & $\begin{array}{l}\text { c) If your friends or colleagues ask you for advice, how likely is it that } \\
\text { you would recommend this bank? (x24) }\end{array}$ \\
\hline
\end{tabular}




\section{Numerical example}

\subsection{Data collection and variables definition}

We sampled 65 customers of a Chinese commercial bank and conducted a questionnaire survey. After eliminating missing values and illogical responses, we got 61 valid questionnaires $(93.8 \%)$. The Latent Variables and Manifest Variables of customer loyalty SEM are defined as in Table1.

All the items are scaled from 1 to 10 . Scale 1 expresses a very negative point of view on the product and service, while scale 10 a very positive opinion.

\subsection{Data analysis}

Since LISREL requires that observed variables should meet normal distribution, we checked our sample data. Using One-Sample Kolmogorov-Smirnov Test, it can be found out that our data failed to meet normal distribution. Here is an example, the observed value of variable $x 12$, to illustrate the case. Histogram of manifest variable $\mathrm{x} 12$ is as follows.

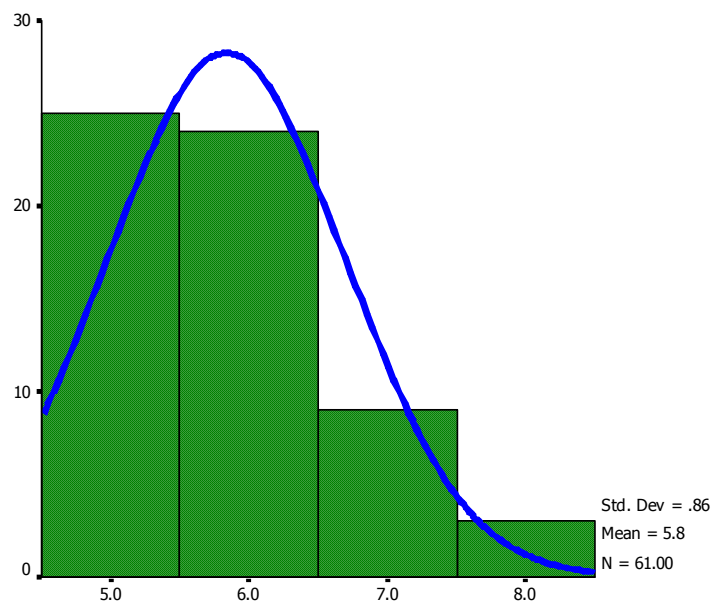

Figure 3: Histogram of manifest variable x12.

From the histogram, it is not obvious whether $\mathrm{x} 12$ has normal distribution. Therefore we conduct One-Sample Kolmogorov-Smirnov Test. Table 2 shows the results.

It can be seen from Table 2 that asymptotic significance (two-tailed) of $\mathrm{x} 12$ is 0.001. It is less than 0.05 significance level and does not have normal distribution. 
Table 2: One-sample Kolmogorov-Smirnov test.

\begin{tabular}{|ll|l|}
\hline & & $\mathrm{X} 12$ \\
\hline $\mathrm{N}$ & & 61 \\
Normal Parameters(a,b) & Mean & 5.8361 \\
& Std. Deviation & .85985 \\
Most Extreme Differences & Absolute & .244 \\
& Positive & .244 \\
& Negative & -.166 \\
Kolmogorov-Smirnov Z & & 1.909 \\
Asymp. Sig. (2-tailed) & & .001 \\
\hline
\end{tabular}

a. Test distribution is Normal. b. Calculated from data.

\subsection{Parameters estimation}

Utilizing the survey data, PLS estimation procedure is used to estimate the parameters of SEM. After five iterations, the parameters' convergence is obtained.

\subsubsection{Measurement model}

$$
\begin{gathered}
\xi 1=0.7369 * \mathrm{x} 1+0.0319 * \mathrm{x} 2+0.0092 * \mathrm{x} 3 \\
\xi 2=0.7182 * \mathrm{x} 4+0.1497 * \mathrm{x} 5+0.0921 * \mathrm{x} 6 \\
\xi 3=0.0734 * \mathrm{x} 7+0.3629 * \mathrm{x} 8+0.3137 * \mathrm{x} 9+0.0141 * \mathrm{x} 10+0.0780 * \mathrm{x} 11 \\
+0.2679 * \mathrm{x} 12+0.0226 * \mathrm{x} 13+0.1183 * \mathrm{x} 14 \\
\xi 4=0.5589 * \mathrm{x} 15+0.3828 * \mathrm{x} 16 \\
\xi 5=0.5609 * \mathrm{x} 17+0.1984 * \mathrm{x} 18+0.3728 * \mathrm{x} 19 \\
\xi 6=0.5603 * \mathrm{x} 20+0.3364 * \mathrm{x} 21 \\
\xi 7=0.3654 * \mathrm{x} 22+0.0714 * \mathrm{x} 23+0.5082 * \mathrm{x} 24
\end{gathered}
$$

\subsubsection{Structure equation model}

$$
\begin{gathered}
\xi 2=0.6544 * \xi 1 \\
\xi 3=0.3851 * \xi 2 \\
\xi 4=0.2212 * \xi 2+0.4479 * \xi 3 \\
\xi 5=0.0765 * \xi 2+0.7001 * \xi 3+0.1597 * \xi 4 \\
\xi 6=-0.6632 * \xi 5 \\
\xi 7=0.2472 * \xi 1+0.7483 * \xi 5-0.3044 * \xi 6
\end{gathered}
$$




\subsection{Customer Loyalty Index (CLI)}

$$
C L I=\frac{10}{n}\left[\sum_{i=1}^{n} \pi_{i}\left(\frac{1}{m} \sum_{j=1}^{m} y_{i j}\right)\right]=45.0894
$$

\subsection{The implications from the results of the example}

1) Customer loyalty has a significant impact on Customer Satisfaction. Therefore to retain its customers, the commercial bank must make great efforts to enhance Customer Satisfaction.

2) Corporation image has some impact on Customer Loyalty, but it is not as important as Customer Satisfaction. It means that good image can help the commercial bank to attract customers, but what affect the commercial bank's customer retention most is Customer Satisfaction.

3) Customer complaints have certain negative impacts on customer loyalty. So the commercial bank should raise the service quality, deal with customer complains seriously and timely, and reduce the negative impacts to the minimum.

4) Perceived Quality has significant impact on Customer Satisfaction, so the commercial bank must improve their service level to enhance Customer Satisfaction.

5) Several manifest variables have significant impact on perceived quality, they are listed in descending order by their influence as follows: service attitude of bank clerks, technical level, bank's capacity to meet customers' personal business demand and customers' waiting time .

6) Perceived Value has some positive impact on Customer Satisfaction, but its influence degree is much less than Perceived Quality. It indicates that at present the fees and prices of this bank are relatively reasonable, what customers care most is the service quality offered by this bank.

7) The Customer Loyalty Index (CLI) of this bank is only 45.0894, which is much less than the maximum CLI (100). It means that this bank's customer retention is poor, and it must take powerful measures to keep its customers.

\section{Conclusion}

In this paper, according to the situation of the bank, the Structural Equation Model was constructed to study the relationships among customer loyalty and some factors. PLS procedure was employed to estimate the parameters of SEM based on a survey among 65 customers of a bank. From this bank's customer loyalty SEM we can find out that service quality and bank's capacity to meet customers' personal business demand are the most important factors influencing the commercial bank's customer retention. Only by sticking to be customercentred and reinforcing customer relationship management, can the bank win the drastic competition in the Chinese finance market. 


\section{References}

[1] G. Hartfeil. Bank One Measures Profitability of Customers, Not Just Products. Journal of Retail Banking Services, 18(2) pp.24-31,1996.

[2] Michael T. Maloney, Robert E. McCormick and Raymond D. Sauer. Customer Choice, Customer Value: An Analysis of Retail Competition in America's Electric Industry, Washington, DC: Citizens for a Sound Economy Foundation, pp.151-169,1996.

[3] RL Desatnick, D Detzel. Managing to keep the customer, Boston, Massachusetts: Houghton Mifflin,1988.

[4] Kuehn, A. A, An Analysis of the Dynamics of Consumer Behaviour and Its Implications for Marketing Management. Ph.D. dissertation, Graduate School of Industrial Administration, Carnegie Institute of Technology, 1958.

[5] Lipstein, B. The dynamics of brand loyalty and brand switching. Proceedings of 5th Annual Conference of the Advertising Research Foundation, September 25th, pp.101-108,1959.

[6] Massey, W.F., Montgomery, D.B. and Morrison, D.G. Stochastic models of buyer behaviour. Cambridge: MIT Press, 1970.

[7] Cunningham, R.M. Brand loyalty-What, where, how much? Harvard Business Review, 34(Jan-Feb), pp.116-128,1956.

[8] Brody, RP and Cunningham. Personality Variables and the Consumer Decision Process. Journal of Marketing Research, 10, pp.50-57,1968.

[9] A. Magi, C. Julander. Perceived service quality and customer satisfaction in a store performance framework-An empirical study of Swedish grocery retailers. Journal of Retailing and Consumer Services, 3 (1), pp.3341,1996 .

[10] Hughes, C. E. Designing Products for Maximum Customer Satisfaction. IEEE, 1-5,1996.

[11] Torsten J. Gerpott, Wolfgang Rams and Andreas Schindler. Customer retention, loyalty, and satisfaction in the German mobile cellular telecommunications market. Telecommunications Policy, 25(4), pp. 249269, 2001.

[12] David W. Wallace, Joan L. Gieseb, and Jean L. Johnson. Customer retailer loyalty in the context of multiple channel strategies. Journal of Retailing, 80(4), pp. 249-263, 2004.

[13] Hee-Su Kim, and Choong-Han Yoon. Determinants of subscriber churn and customer loyalty in the Korean mobile telephony market. Telecommunications Policy, 28(9), pp. 751-765,2004.

[14] C. Fornell, M.D. Johnson, E.W. Anderson. The American customer satisfaction index: nature, purse, and findings, J. Mark. 60, pp. 7-18,1996.

[15] Jae Cha. CFI Group Methodology: PLS, Bridging Measurement and Management, Issue 2, 2000.

[16] Wynne W. Chin. Partial Least Squares For Researchers: An overview and presentation of recent advances using the PLS approach, discnt.cba.uh.edu/chin/indx.html. 